\title{
Acute toxicity of nickel nanoparticles in rats after intravenous injection
}

This article was published in the following Dove Press journal:

International Journal of Nanomedicine

12 March 2014

Number of times this article has been viewed

\section{Ruth R Magaye ${ }^{1, *}$ \\ Xia Yue ${ }^{1, *}$ \\ Baobo Zou' \\ Hongbo Shi' \\ Hongsheng $\mathrm{Yu}^{2}$ \\ Kui Liu' \\ Xialu Lin' \\ Jin $\mathrm{Xu}^{\prime}$ \\ Cui Yang ${ }^{3}$ \\ Aiguo $\mathrm{Wu}^{3}$ \\ Jinshun Zhao'}

'Public Health Department, ${ }^{2}$ Affiliated Hospital of Medical School, Zhejiang Provincial Key Laboratory of Pathological and Physiological

Technology, Ningbo University, ${ }^{3}$ Key Laboratory of Magnetic Materials and Devices, Division of Functional Materials and Nano-devices, Ningbo Institute of Materials Technology and Engineering (NIMTE), Chinese Academy of Sciences, Ningbo, People's Republic of China

*These authors contributed equally to this work

Correspondence: Baobo Zou

Public Health Department, Zhejiang

Provincial Key Laboratory of Pathological and Physiological Technology,

Ningbo University, 818 Fenghua Road,

Jiangbei District, Ningbo,

People's Republic of China

Email zoubaobo@nbu.edu.cn

Jinshun Zhao

Public Health Department, Zhejiang

Provincial Key Laboratory of Pathological and Physiological Technology,

Ningbo University, 818 Fenghua Road, jiangbei District, Ningbo,

People's Republic of China

Email jinshunzhao@nbu.edu.cn
Abstract: This study was carried out to add scientific data in regard to the use of metallic nanoparticles in nanomedicine. The acute toxicity of nickel (Ni) nanoparticles ( $50 \mathrm{~nm}$ ), intravenously injected through the dorsal penile vein of Sprague Dawley rats was evaluated in this study. Fourteen days after injection, Ni nanoparticles induced liver and spleen injury, lung inflammation, and caused cardiac toxicity. These results indicate that precautionary measures should be taken with regard to the use of $\mathrm{Ni}$ nanoparticles or $\mathrm{Ni}$ compounds in nanomedicine.

Keywords: nickel, nanoparticles, intravenous, acute toxicity

\section{Introduction}

In recent times, the medical industry has seen many improvements and advances in the treatment and diagnosis of diseases because of nanotechnology. Major advances have taken place in diagnostics and treatment with the development of improved contrast agents $^{1-5}$ and drug delivery vehicles. ${ }^{6-8}$ The use of metallic nanoparticles and compounds generated with metallic nanoparticles have been paramount to these advances. Nickel $(\mathrm{Ni})$ and $\mathrm{Ni}$ compound nanoparticles are among the compounds being investigated; for example, nickel ferrite $\left(\mathrm{Ni}-\mathrm{Fe}_{2} \mathrm{O}_{4}\right) \cdot{ }^{9,10}$ The physicochemical properties of magnetic nanoparticles, such as $\mathrm{Ni}$, are constantly being improved for other biological applications, which includes magnetically-guided delivery systems for different therapeutics. ${ }^{11}$ An in vitro study has also shown that functionalized Ni nanoparticles capped with positively charged tetraheptylammonium can efficiently enhance the permeation and uptake of quercetin into hepatocellular carcinoma cells (SMMC-7721), implying that Ni nanoparticles have potential for cancer biomedical and chemotherapeutic applications. ${ }^{12}$ Other groups have also investigated the use of Ni nanoparticles for chemotherapeutic applications, such as the accumulation of the anticancer drug daunorubicin in leukemia cells. ${ }^{13,14}$ The challenge lies in the application of these methods in vivo, where factors, such as plasma protein interactions ${ }^{15}$ and particle dissociation, influence the end result. These factors can also contribute to nanoparticle toxicity. In addition, many metal particles, such as $\mathrm{Ni}$, have very poor solubility in water, which may contribute to their toxicity effects.

With respect to nanomedicine, the in vivo delivery of these nanoparticles is accomplished through parenteral methods, such as intravenous administration. Intravenous administration of substances bypasses the first-pass effect, allowing higher concentrations to be delivered throughout the body. Dorsal penile vein (DPV) exposure is one of the methods of intravenous administration used in in vivo animal experiments, and nanoparticles are commonly used as contrast agents ${ }^{16}$ in 
DPV exposure studies. DPV, as well as tail vein injection, are indispensable tools for determining the toxicity of test substances that are delivered intravenously. Therefore, identifying the target tissues for intravenously administered metallic Ni nanoparticles and their toxicity in in vivo models builds a foundation for determining the target tissues of other functionalized $\mathrm{Ni}$ nanoparticles that are being explored. This may also lead to improved target therapy and systemic monitoring. In this study, we evaluate the acute toxicity of metallic Ni nanoparticles administered through the DPV of Sprague Dawley rats using basic medical diagnostic tools, such as histopathological, biochemical, and hematological tests.

\section{Materials and methods Materials}

Ni nanoparticles were obtained from Danyang City Alloy and Steel Refinery Co, Ltd (Danyang, Jiangsu, People's Republic of China) (50 nm). Isoflurane was obtained from Sun Chemical Technology Co, Ltd (Shanghai, People's Republic of China). A Hitachi 7600-110 autoanalyzer (Hitachi Ltd, Tokyo, Japan) and blood analyzer (Sysmex XT-1800i; Sysmex Co, Kobe, Japan) were used for biochemical and hematological analysis, respectively. Sprague Dawley rats were purchased from Zhejiang Provincial Laboratory Animal Science Center (Hangzhou, Zhejiang, People's Repulic of China).

\section{Methods}

\section{Ni nanoparticle preparation}

A stock suspension of $\mathrm{Ni}$ nanoparticles was prepared in normal saline $(10 \mathrm{mg} / \mathrm{mL})$ by sonication for 30 seconds using a Branson sonifier 450 (Branson Ultrasonics Corp, Danbury, CT, USA). The particle suspensions were kept on ice for 15 seconds and sonicated again on ice for a total of 3 minutes at a power of $400 \mathrm{~W}$. Before use, Ni nanoparticles were diluted to desired concentrations in fresh saline. All samples were prepared under sterile conditions.

\section{Detection of size distribution}

The size distribution of Ni nanoparticles was detected using scanning electron microscopy (SEM) (Hitachi S-4800; Hitachi Ltd). Briefly, Ni nanoparticles were prepared by sonication. The samples were then diluted in double-distilled water and air-dried onto a carbon planchet. Images were collected on SEM. Optimas 6.5 image analysis software (Media Cybernetics, Bethesda, MD, USA) was used to measure the diameter of Ni nanoparticles.

\section{Animal husbandry}

Sprague Dawley rats were selected as the animal model for the acute toxicity study of Ni nanoparticles. All animals (16 rats) were housed according to standard animal housing conditions (relative humidity $60 \% \pm 10 \%$, room temperature $20^{\circ} \mathrm{C} \pm 2{ }^{\circ} \mathrm{C}$, and 12 hour light/dark cycle). Food and water were provided ad libitum. All animals were kept in stress free, hygienic, and animal-friendly conditions. Animal study protocols were approved by the Ningbo University Institutional Animal Care and Use Committee.

\section{Study design and dose selection}

Healthy rats (12 weeks old) were selected and randomly divided into one control group and three experimental groups ( $1 \mathrm{mg} / \mathrm{kg}, 10 \mathrm{mg} / \mathrm{kg}$, and $20 \mathrm{mg} / \mathrm{kg}$ ) with four male rats in each group. A staged approach to dosing method was used to select the dose ranges. Ni nanoparticles were suspended in normal saline and vortexed. The animals were anesthetized with isoflurane $(5 \%)$ prior to injection of $\mathrm{Ni}$ nanoparticles ( $2 \mathrm{~mL}$ of particle suspension) through the DPV, once at day 1 and once at day 14 . The control group received an injection of $2 \mathrm{~mL}$ normal saline. The rats were anesthetized with isoflurane before sacrifice at day 15 .

\section{Hematological analysis}

After the rats were anesthetized, blood for hematological analysis was collected into a test tube containing $20 \mathrm{mg} / \mathrm{mL}$ ethylenediaminetetraacetic acid (EDTA) anticoagulant. The rat was sacrificed at the same time and $5.0 \mathrm{~mL}$ blood was collected by incision of the femoral artery; $1 \mathrm{~mL}$ of this sample was collected in a tube with EDTA for complete blood count (CBC) and the remaining $4 \mathrm{~mL}$ was used for biochemical analysis.

The blood was analyzed for the number of erythrocytes, platelets, total white blood cells (WBCs) as well as WBC differentials using an automated blood analyzer (Sysmex XT-1800i, Sysmex). In addition to these, hemoglobin ( $\mathrm{Hb})$ and mean corpuscular hemoglobin concentrate (MCHC) were also analyzed.

\section{Biochemical analysis}

The enzymatic parameters related to liver, kidney, and cardiac function were detected using an auto analyzer (Hitachi 7600-110; Hitachi Ltd). Analysis of lipid and serum electrolytes were also included.

\section{Organ to body weight coefficient}

The body weight of all rats were recorded before sacrifice. Organs, such as the heart, lung, liver, spleen, kidney, brain, and 
testes were removed and weighed immediately. After weighing the body and organs, the coefficients of liver, heart, lung, spleen, kidney, brain, and testes weight to body weight were calculated as the ratio of tissue wet weight $(\mathrm{g})$ to body weight $(\mathrm{g})$.

\section{Histopathological examination}

The organs were immediately fixed in $10 \%$ formalin for histopathological examination. The formalin fixed tissues were stored at $4{ }^{\circ} \mathrm{C}$ until examination. Tissues were processed using standard histological laboratory techniques. Briefly, using a microtome, 3-4 $\mu \mathrm{m}$ sections were cut then stained with hematoxylin and eosin (H\&E) stain following a standard staining protocol.

\section{Statistical analysis}

Statistical analysis was performed using SAS statistical software (SAS Institute Inc., Cary, NC, USA). The Student's $t$-test was used to compare the difference between the experimental groups and the control group. The statistical significance for all tests was set at $P \leq 0.05$. The results are presented as means \pm standard deviation (SD).

\section{Results}

\section{The average size distribution of Ni nanoparticles}

The average size distribution of the $\mathrm{Ni}$ nanoparticles was $40.50 \pm 18.60 \mathrm{~nm}$ as detected by Optimas 6.5 image analysis software (Media Cybernetics). Images of $\mathrm{Ni}$ nanoparticles were captured by SEM (Figure 1) and Table 1 gives the physicochemical characteristics of the metallic $\mathrm{Ni}$ nanoparticles. The size distribution of Ni nanoparticles agglomerates/aggregates in saline was observed under a light microscope (Figure 2).

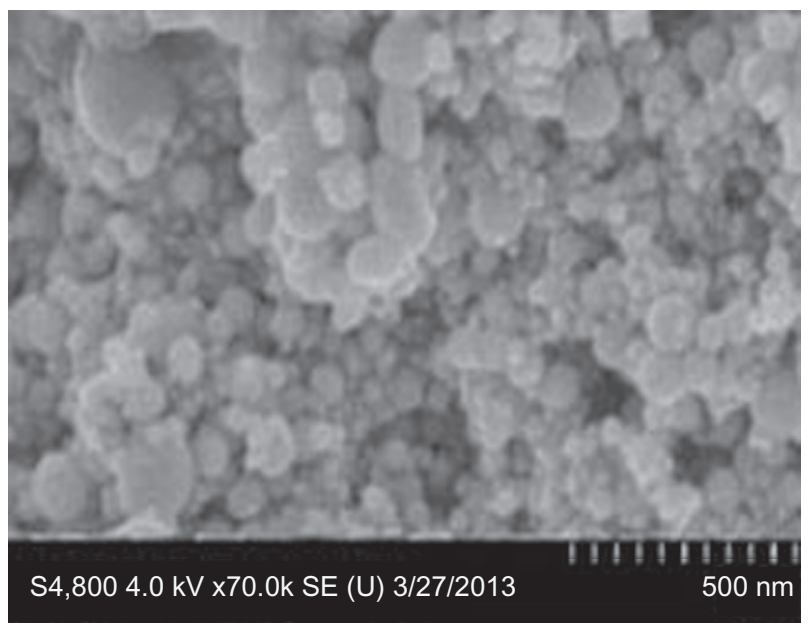

Figure I Image of nickel nanoparticles captured by scanning electron microscopy.
Table I Physicochemical characteristics of metallic Ni nanoparticles

\begin{tabular}{lllll}
\hline Sample & \multicolumn{2}{l}{ Primary size measured by } & $\begin{array}{l}\text { Surface } \\
\text { area } \\
\left(\mathbf{m}^{2} / \mathbf{g}\right)\end{array}$ & Composition \\
\cline { 2 - 5 } & Manufacturer & SEM & 28 & $99.8 \% \mathrm{Ni}$ \\
\hline $\mathrm{Ni} \mathrm{Nano}$ & $50 \mathrm{~nm}$ & $40.50 \pm 18.6 \mathrm{~nm}$ & & $0.01 \% \mathrm{Co}$ \\
& & & & $0.0068 \% \mathrm{Ca}$
\end{tabular}

Abbreviations: Nano, nanoparticles; Ni, nickel; SEM, scanning electron microscope.

\section{Coefficient of tissues}

Throughout the study period, no behavioral changes or unusual responses were observed in the animals treated with Ni nanoparticles.

The heart, lung, spleen, kidney, brain, and testes of animals treated with Ni nanoparticles had no significant differences in organ weight/body weight coefficients (Figure 3). The organ weight/body weight coefficient of the liver of rats treated with Ni nanoparticles increased significantly in a dose dependent manner.

\section{Hematological analysis}

Ni nanoparticles significantly increased the WBC count in all dose groups, most significantly in the $1 \mathrm{mg} / \mathrm{kg}$ dose group,

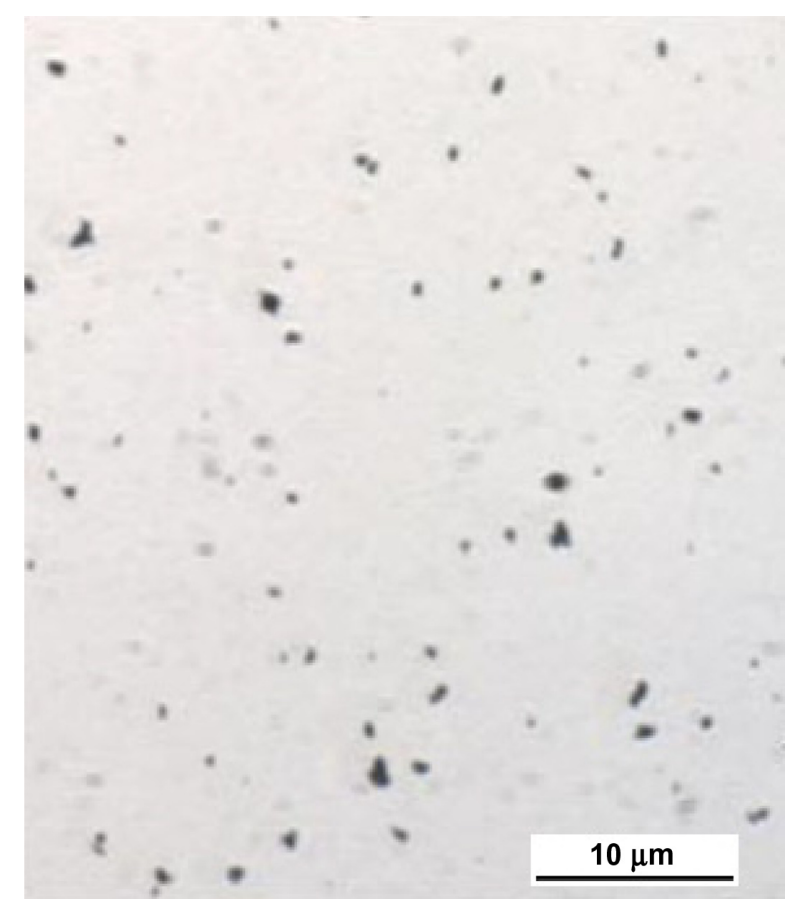

Figure $2 \mathrm{Ni}$ nanoparticles agglomerates/aggregates formation in saline under light microscopy.

Notes: Ni nanoparticles in saline were dropped onto a glass slide. Agglomerates/ aggregates of $\mathrm{Ni}$ nanoparticles in solution were checked under the microscope $(400 \mathrm{X})$. After precipitation, the larger agglomerates/aggregates were in the size range of 100-600 nm, and the smaller agglomerates/aggregates were not visible under the light microscope at 400X.

Abbreviation: Ni, nickel. 

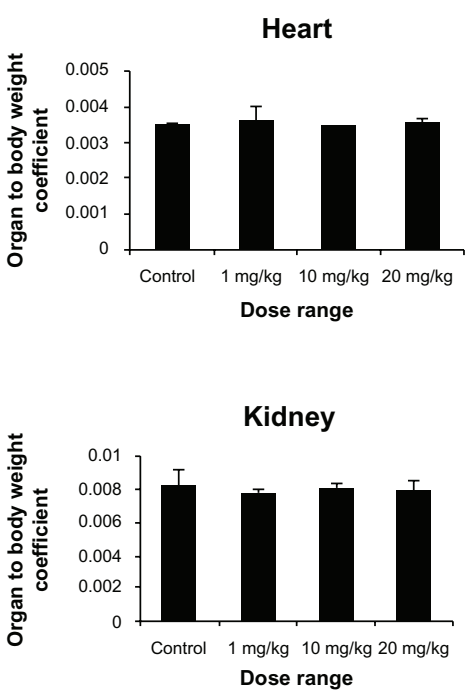

Testes

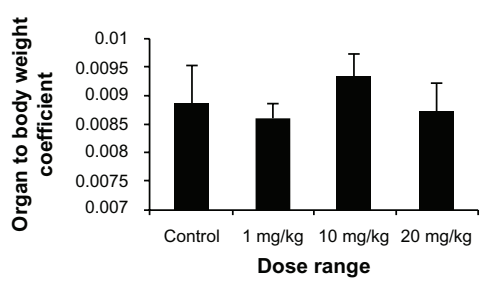

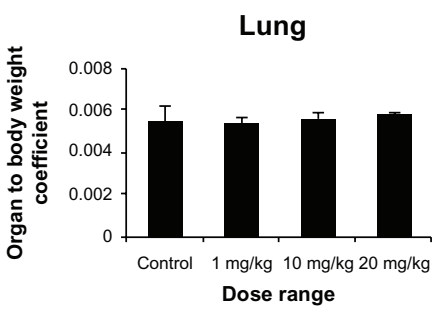

Spleen

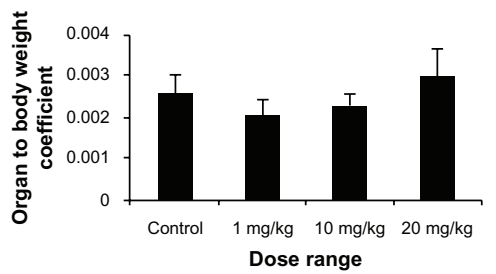

Liver

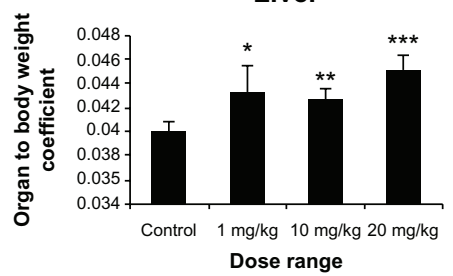

Brain

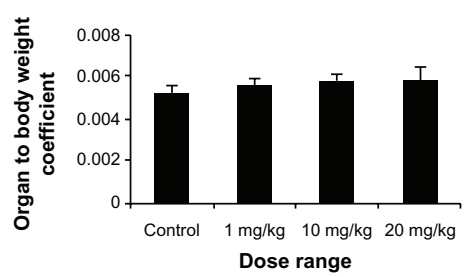

Figure 3 Organ coefficient values of rats exposed to Ni nanoparticles through DPV injection.

Notes: $* P \leq 0.05, * * P \leq 0.01$, and $* * * P \leq 0.00$ I versus control.

Abbreviations: $\mathrm{Ni}$, nickel; DPV, dorsal penile vein.

and the $\mathrm{RBC}$ count, $\mathrm{Hb}$ concentration, and the monocyte percentage $(\mathrm{Mo} \%)$ in the $20 \mathrm{mg} / \mathrm{kg}$ dose group. Conversely, the neutrophil percentage $(\mathrm{Ne} \%)$ at $10 \mathrm{mg} / \mathrm{kg}$ was significantly decreased. No significant changes were observed in the other hematological parameters measured (Table 1).

\section{Biochemical analysis}

The biochemical parameters, included the liver, renal, cardiac and lipid profiles, and serum electrolytes are shown in Table 3. The liver profiles showed that the Ni nanoparticles induced significant increases in serum albumin levels at $1 \mathrm{mg} / \mathrm{kg}$ and alkaline phosphatase (ALP) with the $20 \mathrm{mg} / \mathrm{kg}$ dose. Serum levels of alanine aminotransferase (ALT) with $1 \mathrm{mg} / \mathrm{kg}$, total bilirubin with $10 \mathrm{mg} / \mathrm{kg}$ and $20 \mathrm{mg} / \mathrm{kg}$ doses, and direct bilirubin with the $20 \mathrm{mg} / \mathrm{kg}$ dose were significantly decreased. No significant differences in the serum levels of total protein and aspartate aminotransferase (AST) were observed in the liver profile. The renal profile parameters (creatinine, uric acid, and blood urea nitrogen [BUN]), were not significantly different between any dose group compared to controls. Serum creatine kinase (CK) levels with $1 \mathrm{mg} / \mathrm{kg}$ and $20 \mathrm{mg} / \mathrm{kg}$ were significantly decreased, while no significant changes were observed for serum CK-MB levels compared to controls. The lipid profile showed that there were significant decreases in serum levels of low-density lipoprotein (LDL) cholesterol with $1 \mathrm{mg} / \mathrm{kg}$ and cholesterol with the $10 \mathrm{mg} /$ $\mathrm{kg}$ dose, while with $20 \mathrm{mg} / \mathrm{kg}$ dose the serum cholesterol levels were significantly increased. Significant increases in the serum levels of triglycerides $(1 \mathrm{mg} / \mathrm{kg}$ and $10 \mathrm{mg} / \mathrm{kg}$ doses) and apolipoprotein E (Apo-E; $10 \mathrm{mg} / \mathrm{kg}$ and $20 \mathrm{mg} / \mathrm{kg}$ doses) were also observed. Phosphate levels in the serum had a significant decrease in a dose dependent manner compared to controls, and the magnesium levels were also decreased with the $10 \mathrm{mg} / \mathrm{kg}$ and $20 \mathrm{mg} / \mathrm{kg}$ doses.

\section{Histopathological examination}

The histological tissue sections of the rat lung, liver, and spleen treated with $\mathrm{Ni}$ nanoparticles showed pathological changes as revealed in Figures 4, 5, and 6, respectively. No significant pathological changes were observed in other tissues (not shown).

Ni nanoparticles caused lung inflammation in the rats with all dose ranges. The Ni nanoparticle treatments were associated with mild to moderate lymphocytic and eosinophilic 

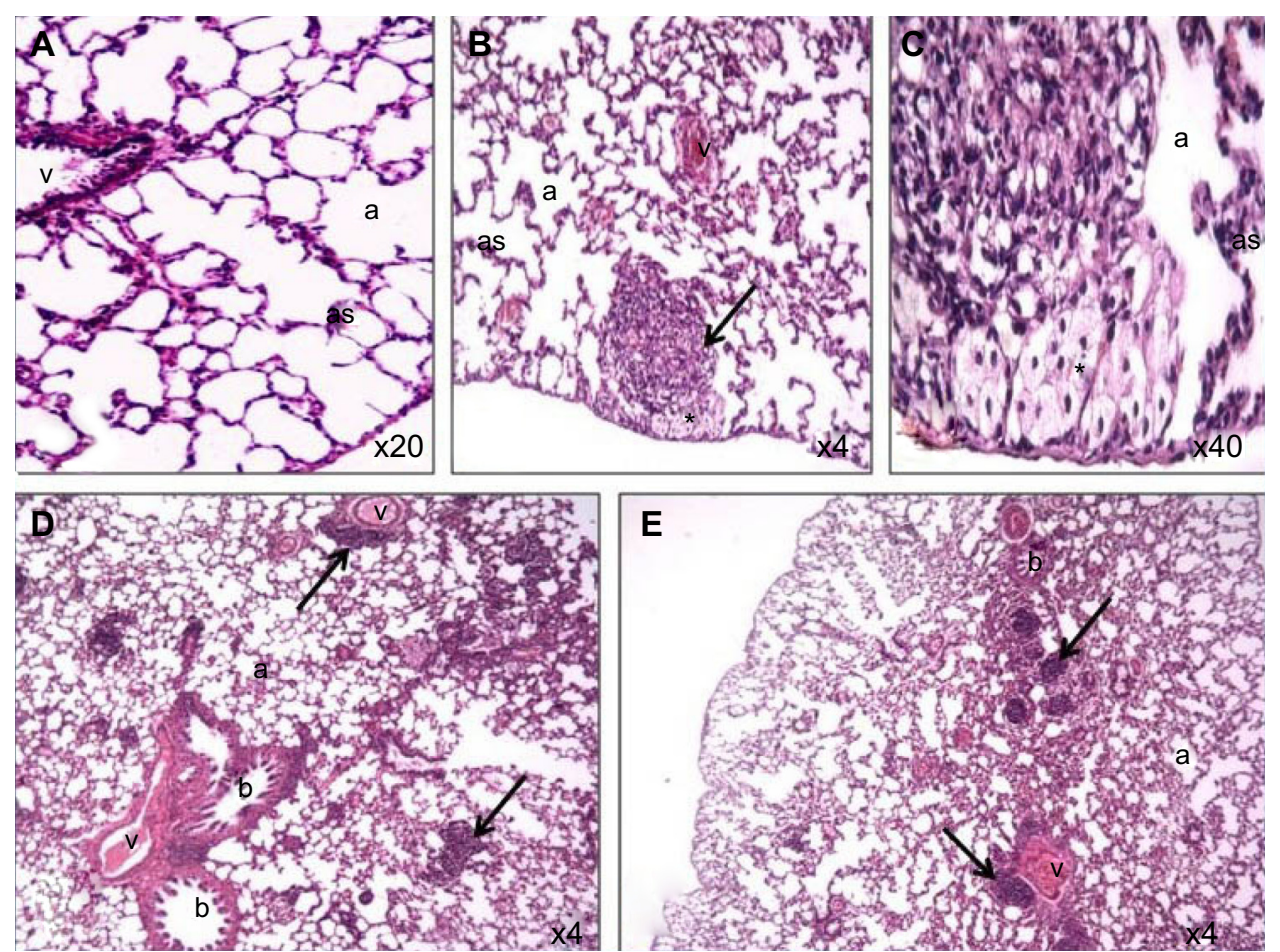

Figure 4 Photomicrograph of lung tissue sections of rats treated with Ni nanoparticles.

Notes: (A) Control (200X); (B) lymphocytic and eosinophilic infiltrates with thickening of alveolar walls and foamy macrophages (dark arrow) with the 20 mg/kg dose of $\mathrm{Ni}$ nanoparticles (40X); (C) foamy macrophages (indicated by the asterisk) with $20 \mathrm{mg} / \mathrm{kg} \mathrm{Ni}$ nanoparticles (400X); (D) lymphocytic and eosinophilic infiltrates (dark arrow) with I mg/kg Ni nanoparticles (40X); (E) lymphocytic and eosinophilic infiltrates (dark arrow) with $10 \mathrm{mg} / \mathrm{kg}$ Ni nanoparticles (40X).

Abbreviations: a, alveolar space; as, alveolar septae; b, bronchioles; $\mathrm{Ni}$, nickel; $\mathrm{v}$, veins.
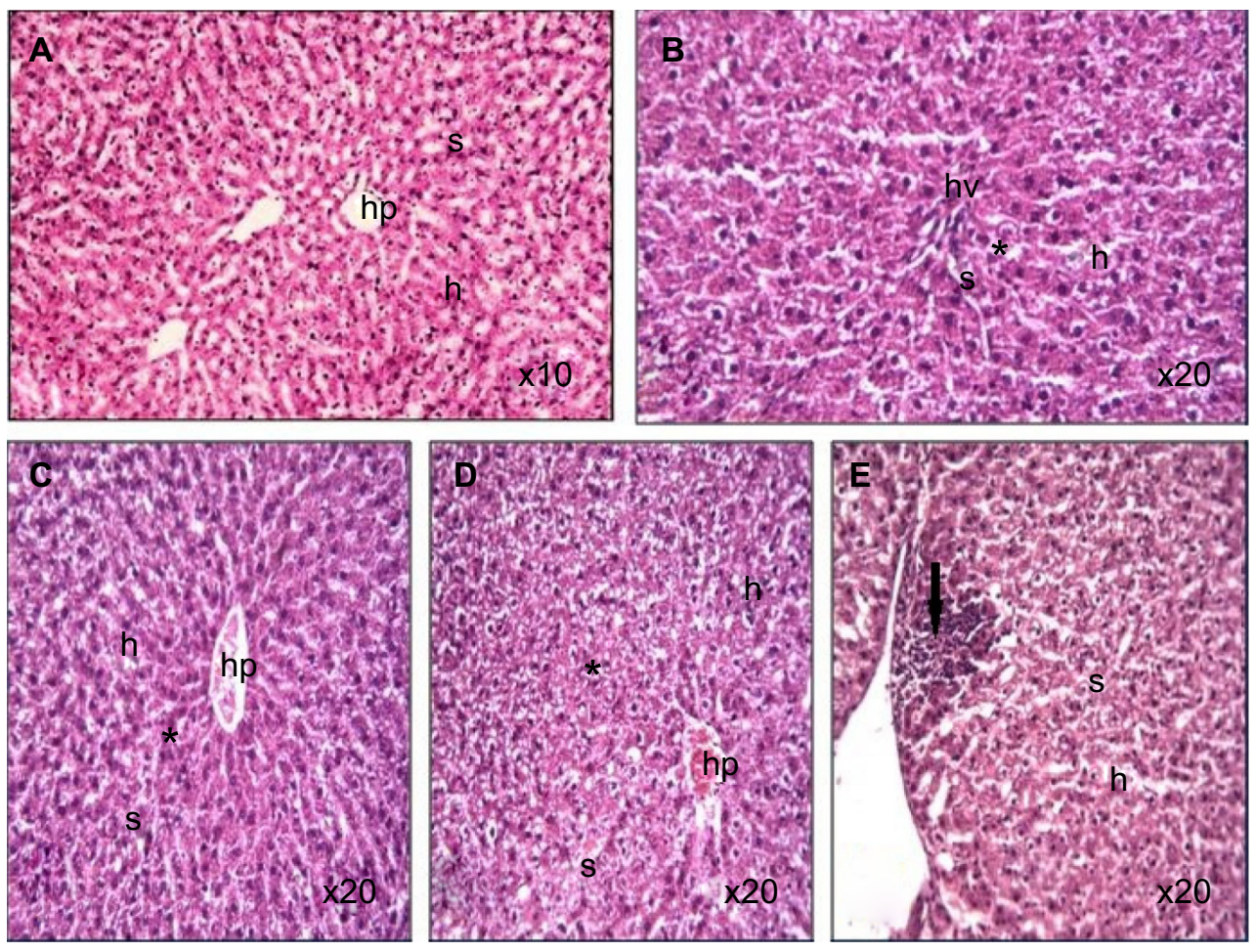

Figure 5 Photomicrograph of liver tissue sections of rats treated with Ni nanoparticles.

Notes: (A) control (I00X); (B-D) distorted architecture (indicated by the asterisk) of the liver sinusoids with $10 \mathrm{mg} / \mathrm{kg} \mathrm{Ni}$ nanoparticles (200X); (E) lymphoctic and eosinophilic infiltrates at the periphery of the liver (dark arrow) with $20 \mathrm{mg} / \mathrm{kg} \mathrm{Ni} \mathrm{nanoparticles} \mathrm{(200X).}$

Abbreviations: $\mathrm{h}$, hepatocytes; hp, hepatic portal; Ni, nickel; s, sinusoids; hv, hepatic vein. 

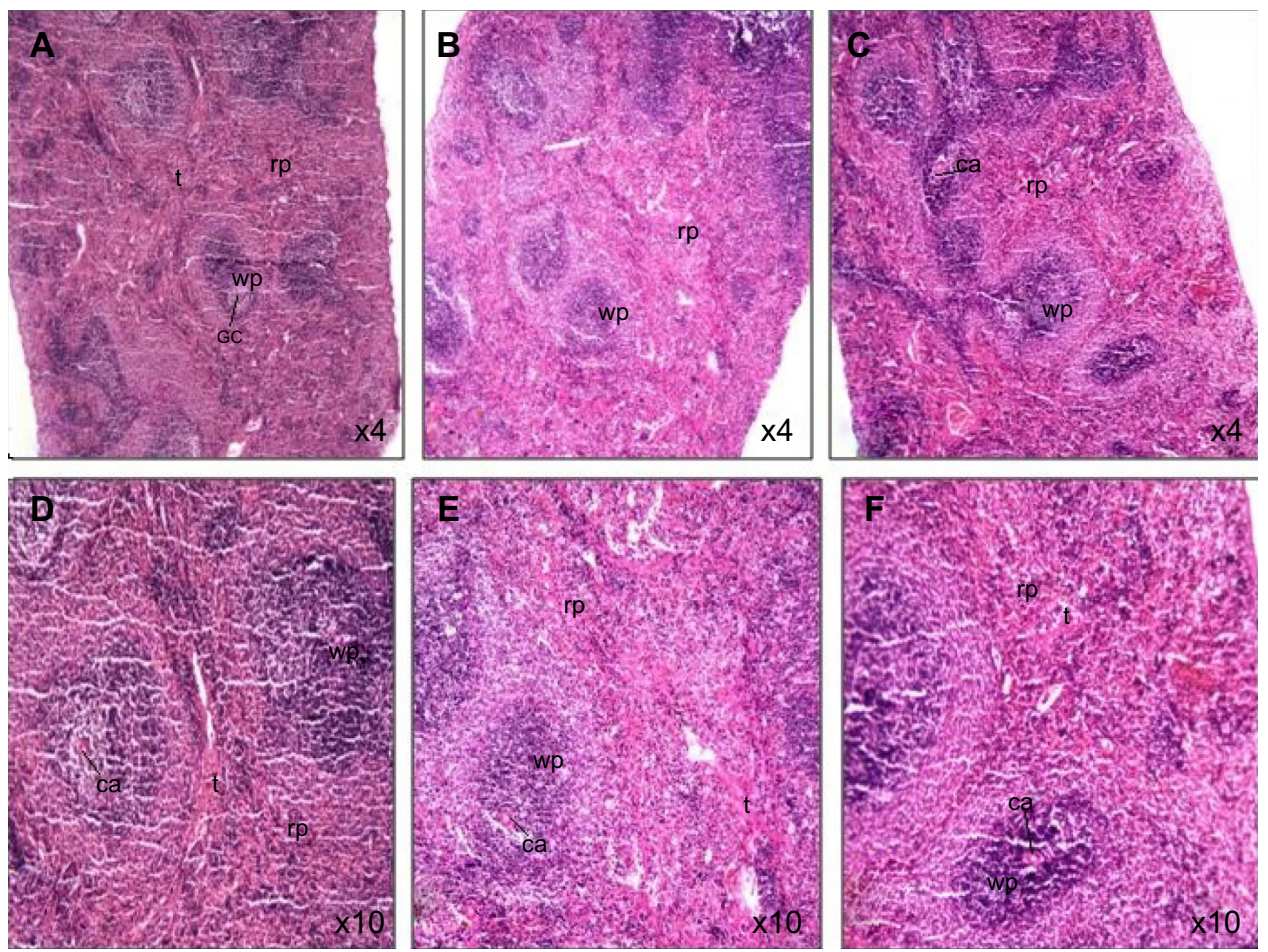

Figure 6 Photomicrograph of spleen tissue sections of rats treated with Ni nanoparticles.

Notes: (A and D) Show normal spleen morphology with I mg/kg of Ni nanoparticles (X40 and XI00, respectively); (B and E) show increased red pulp area with 10 mg/kg of Ni nanoparticles (X40 and X100, respectively); (C and F) show increased red pulp area with $20 \mathrm{mg} / \mathrm{kg}$ of Ni nanoparticles (X40 and XI00, respectively).

Abbreviations: ca, central artery; gc, germinal center; Ni, nickel; rp, red pulp; t, trabeculae; wp, white pulp.

infiltration in the alveolar, peribronchial, and perivascular regions (Figure 4B, D, and E) compared to the controls (Figure 4A). With the $20 \mathrm{mg} / \mathrm{kg}$ dose, foamy macrophages were observed in the alveolar spaces (Figure 4C). Even though Ni nanoparticles caused thickening of alveolar septae, the architecture was identifiable in all dose groups.

$\mathrm{Ni}$ nanoparticle treatment in rats was associated with lymphocytic infiltration at the periphery of the liver with the $20 \mathrm{mg} / \mathrm{kg}$ dose (Figure 5E) compared to controls (Figure 5A). In addition, the liver with $1 \mathrm{mg} / \mathrm{kg}, 10 \mathrm{mg} / \mathrm{kg}$, and $20 \mathrm{mg} / \mathrm{kg}$ doses (Figure 5B, C, and D) showed that the normal architecture of the liver parenchyma was distorted. Ni nanoparticles also caused changes in spleen tissue morphology. The changes were most prominent with the $10 \mathrm{mg} / \mathrm{kg}$ and $20 \mathrm{mg} / \mathrm{kg}$ doses, which showed increased red pulp area (Figure 6C, D, E, and F) compared to the spleen with $1 \mathrm{mg} / \mathrm{kg}$. Figure $6 \mathrm{~A}$ and B show the spleen at $1 \mathrm{mg} / \mathrm{kg}$ with no prominent morphological changes.

\section{Discussion}

Nickel and nickel compounds are widely used in industry ${ }^{17}$ and, recently, in nanomedicine. ${ }^{18}$ Research has shown that intravenous injection of other nanoparticles is more suitable for radiotherapy; ${ }^{19}$ however, the toxicity of intravenously delivered metallic Ni nanoparticles is yet to be fully elucidated. In this study, the acute toxicity of intravenously administered metallic Ni nanoparticles was investigated in rats using standard laboratory tests.

\section{DPV injection of Ni nanoparticles led to inflammatory infiltrates in the lung}

In the lung, histopathological examination showed mild and focal inflammatory infiltrates in the pulmonary parenchyma of Ni nanoparticle treated rats. Most of these infiltrates were observed around the blood vessels and terminal ducts. Apart from slight increases in the size of the alveolar septae, all other pulmonary parenchyma appeared normal. The infiltrates were mostly composed of lymphocytes; $T$ lymphocytes are thought to be both pro and anti-fibrotic. ${ }^{20}$ Other studies involving Ni oxide nanoparticles have also reported the presence of lymphocytic infiltrates in the lung. ${ }^{21}$ In the high dose group, foamy macrophages were observed in the alveolar spaces, which are found in various lung diseases. A study by Yuasa and Kanazawa ${ }^{22}$ found that foamy macrophages can be derived from monocytes in the blood. Our hematological analysis showed that the percentage of monocytes with the $20 \mathrm{mg} / \mathrm{kg}$ dose was also significantly increased (Table 2). These findings suggest that Ni nanoparticles caused acute 
Table 2 Hematological parameters of rats treated with/without Ni nanoparticles through DPV

\begin{tabular}{|c|c|c|c|c|}
\hline \multirow[t]{2}{*}{ Parameters } & \multicolumn{4}{|l|}{ Mean \pm SD } \\
\hline & Control & I mg/kg & 10 mg/kg & $20 \mathrm{mg} / \mathrm{kg}$ \\
\hline WBC & $8.45 \pm 1.66$ & II.78 \pm I** & $10.58 \pm 1.68$ & $10.63 \pm 3.57$ \\
\hline $\mathrm{Ne}(\%)$ & $\mid 9.6 \pm 1$ & $16.83 \pm 1.46 *$ & $14 \pm 0.8 * *$ & $14.17 \pm 0.64^{* *}$ \\
\hline Ly (\%) & $78.65 \pm 3.97$ & $79.93 \pm 3.95$ & $82.78 \pm 3.13$ & $75.78 \pm 3.23$ \\
\hline Mo (\%) & $1.73 \pm 1.2$ & $3.4 \pm 3.31$ & $1.5 \pm 1.7$ & $7.73 \pm 1.20 * * *$ \\
\hline Eo (\%) & $1.43 \pm 1.27$ & $0.8 \pm 0.28$ & $2.5 \pm 3.5$ & $0.78 \pm 0.25$ \\
\hline $\mathrm{RBC}$ & $7.4 \pm 0.13$ & $7.34 \pm 0.12$ & $7.52 \pm 0.03$ & $8.02 \pm 0.05 * *$ \\
\hline $\mathrm{Hb}$ & $|44.67 \pm 3.5|$ & $142.33 \pm 2.08$ & $145.33 \pm 1.16$ & $|57.67 \pm 4.5|^{*}$ \\
\hline $\mathrm{MCHC}$ & $316 \pm 4.32$ & $315 \pm 2.94$ & $320.25 \pm 4.35$ & $321.25 \pm 8.73$ \\
\hline PLT & $992.75 \pm 120.70$ & $\mathrm{I},|38.25 \pm 7| .07$ & $1,026.5 \pm 62.32$ & $1,016.5 \pm 187.77$ \\
\hline
\end{tabular}

Notes: $* P \leq 0.05, * * P \leq 0.01, * * * P \leq 0.001$ versus control.

Abbreviations: DPV, dorsal penile vein; Eo, eosinophil; Hb, hemoglobin; Ly, Lymphocyte; MCHC, mean corpuscular hemoglobin concentrate; Mo, monocyte; Ne, neutrophil; $\mathrm{Ni}$, nickel; PLT, platelet; RBC, red blood cell; SD, standard deviation; WBC, white blood cell.

inflammation and injured the lungs, as monocytes increase with inflammation. ${ }^{23}$

The number of WBCs was increased significantly with the $1 \mathrm{mg} / \mathrm{kg}$ dose of $\mathrm{Ni}$ nanoparticles, and even though the differentials showed that there was an increased monocyte percentage, this was not significant. In the $1 \mathrm{mg} / \mathrm{kg}$ dose group there was a significant decrease $(P \leq 0.05)$ in the percentage of neutrophils, while with $10 \mathrm{mg} / \mathrm{kg}$ and $20 \mathrm{mg} / \mathrm{kg}$, the significant decrease $(P \leq 0.01)$ in neutrophil percentage was greater. The RBC numbers increased significantly with the $20 \mathrm{mg} / \mathrm{kg}$ dose, which was concurrent with a significant increase in the $\mathrm{Hb}$ concentration. An increase in RBC count (polycythemia) in the circulation occurs in cases of low oxygen levels, which triggers increased erythropoietin secretion in the kidney; this can be either primary or secondary polycythemia. In this study, the polycythemia may have been a consequence of less oxygen reaching the alveolars due to pulmonary disease. ${ }^{24}$ The increase in the red pulp area as observed in the histological sections of the spleen with the $10 \mathrm{mg} / \mathrm{kg}$ and $20 \mathrm{mg} / \mathrm{kg}$ doses support the hematological findings of increased RBC production. An increase in the red pulp area may be caused by pathological conditions, such as portal hypertension, cardiac failure, or extramedullary hematopoiesis. The spleenic changes observed in this study may be due to extramedullary hematopoiesis produced as a result of hypoxia or inflammatory mediators ${ }^{25}$ released in response to inflammation caused by $\mathrm{Ni}$ nanoparticles. Therefore, as the dose increases, the level of inflammation increases, thus leading to increased red pulp area (extramedullary hematopoiesis) in the spleen. Apart from those that were previously mentioned, all other hematological parameters measured showed no significant changes. Also, the results obtained in this study do not follow a predictable pattern, which is a cause for further studies that may help in refuting or confirming these findings and elucidating the mechanisms associated with this variability.

\section{DPV injection of Ni nanoparticles induced liver injury}

Ni nanoparticle treated rats showed a dose dependent increase in the liver coefficient. This was supported by histopathological examination of the liver that showed distortion of normal liver architecture due to congestion, as evidenced by the decrease in sinusoids compared to the controls. It is also supported by the aggregates of lymphocytic and eosinophilic infiltrates at the periphery of the liver tissue with the $20 \mathrm{mg} / \mathrm{kg}$ dose. This evidence indicates that intravenously injected Ni nanoparticles cause inflammation of the rat liver, which may have led to the changes seen in the liver coefficient (Figure 1). The biochemical analysis of blood serum indicated liver injury with the $20 \mathrm{mg} / \mathrm{kg}$ dose. A significant decrease and increase in the serum levels of total bilirubin and ALP with the $20 \mathrm{mg} / \mathrm{kg}$ dose (Table 3) was observed, respectively. When more than $50 \%$ of the total bilirubin is conjugated (direct) bilirubin, hepatocellular injury can be inferred. ${ }^{26}$ The direct bilirubin level with the $20 \mathrm{mg} / \mathrm{kg}$ dose was significantly increased, implying that hepatocellular injury may have occurred. This is supported by the increased ALP levels in serum. Increases in ALP levels coupled with conjugated hyperbilirubinemia, and a negligible increase in aminotransferase levels, may be present in cholestatic drug reactions. ${ }^{27}$ This implies that intravenously injected $\mathrm{Ni}$ nanoparticles may cause toxic reactions that are similar to those caused by drugs. No significant differences in the other liver profile parameters were observed. With the $20 \mathrm{mg} / \mathrm{kg}$ dose, serum levels of cholesterol was significantly increased. In some liver diseases, increased serum cholesterol levels have been observed. 
Table 3 Biochemical parameters of rats treated with/without Ni nanoparticles through DPV

\begin{tabular}{|c|c|c|c|c|}
\hline \multirow[t]{2}{*}{ Parameters } & \multicolumn{4}{|l|}{ Means \pm SD } \\
\hline & Control & I mg/kg & $10 \mathrm{mg} / \mathrm{kg}$ & $20 \mathrm{mg} / \mathrm{kg}$ \\
\hline \multicolumn{5}{|l|}{ Liver profile } \\
\hline Total protein & $55.2 \pm 2.21$ & $57.63 \pm 2.3$ & $55.08 \pm 1.23$ & $55.97 \pm 1.18$ \\
\hline Albumin & $32.1 \pm 1.39$ & $34.48 \pm 0.82 *$ & $32.35 \pm 0.97$ & $32.98 \pm 0.85$ \\
\hline ALP & $219.75 \pm 22.87$ & $245.75 \pm 17.17$ & $243.5 \pm 44.44$ & $261.75 \pm 13^{* *}$ \\
\hline AST & $140.25 \pm 57.48$ & $100.75 \pm|4.0|$ & $137.5 \pm 9.68$ & $126.67 \pm 25.34$ \\
\hline $\mathrm{ALT}$ & $74.33 \pm 3.21$ & $66.7 \pm 0.67^{*}$ & $7 I \pm 2.65$ & $74.3 \pm 4.72$ \\
\hline Total bilirubin & $I .1 \pm 0.26$ & $0.7 \pm 0.2$ & $0.6 \pm 0.2 *$ & $0.2 \pm 0.06 * *$ \\
\hline Direct bilirubin & $1.43 \pm 0.65$ & $0.67 \pm 0.12$ & $0.6 \pm 0.05$ & $0.27 \pm 0.15^{*}$ \\
\hline \multicolumn{5}{|l|}{ Renal profile } \\
\hline Creatinine & $18 \pm 2.94$ & $16.75 \pm 0.5$ & $|8 \pm| .4 \mid$ & $16.5 \pm 1.29$ \\
\hline Uric acid & $86.75 \pm 20.19$ & $68.75 \pm 10.72$ & $87.75 \pm 12.84$ & $71.25 \pm 21.75$ \\
\hline BUN & $5.56 \pm 0.87$ & $5.63 \pm 0.21$ & $5.21 \pm 0.66$ & $6.04 \pm 0.39$ \\
\hline \multicolumn{5}{|l|}{ Cardiac profile } \\
\hline CK & $4,197.3 \pm 2,634.9$ & $468.33 \pm 107.2^{*}$ & $2,779.7 \pm 205.3$ & $1,948.7 \pm 196.5^{*}$ \\
\hline CK-MB & $739.5 \pm 382.8$ & $442.5 \pm 71.08$ & $685.25 \pm 121.6$ & $528.75 \pm 248.11$ \\
\hline \multicolumn{5}{|l|}{ Lipid profile } \\
\hline LDL-cholesterol & $0.2 \pm 0.02$ & $0.15 \pm 0.01 *$ & $0.17 \pm 0.02$ & $0.19 \pm 0.01$ \\
\hline Cholesterol & $1.87 \pm 0.18$ & $1.84 \pm 0.29$ & $1.73 \pm 0.24 *$ & $2.08 \pm 0.32 *$ \\
\hline Triglycerides & $1.2 \pm 0.12$ & $1.49 \pm 0.17 *$ & $1.38 \pm 0.15^{*}$ & $1.25 \pm 0.15$ \\
\hline Apo-E & $27.3 \pm 0.5$ & $29.67 \pm 1.53$ & $30 \pm 0.5^{*}$ & $31.67 \pm 0.58 * *$ \\
\hline \multicolumn{5}{|l|}{ Serum electrolytes } \\
\hline Magnesium & $0.97 \pm 0.08$ & $0.9 \pm 0.02$ & $0.88 \pm 0.03 *$ & $0.85 \pm 0.03 *$ \\
\hline Phosphate & $2.6 I \pm 0.07$ & $2.48 \pm 0.09$ & $2.22 \pm 0.22 *$ & $2.05 \pm 0.1 * *$ \\
\hline Iron & $41.25 \pm 5.12$ & $41.75 \pm 3.86$ & $42.25 \pm 3.6$ & $46.5 \pm 5$ \\
\hline
\end{tabular}

Notes: $* P \leq 0.05, * * P \leq 0.01$ versus control.

Abbreviations: ALP, alkaline phosphatase; ALT, alanine transaminase; Apo-E, apolipo protein E; AST, aspartate aminotransferase; BUN, blood urea nitrogen; CK, creatine linase; DPV, dorsal penile vein; LDL, low-density lipoprotein; Ni, nickel.

The Apo-E concentration in serum was also significantly increased with the $20 \mathrm{mg} / \mathrm{kg}$ dose. Apart from lipid metabolism, the Apo-E protein is thought to have a variety of functions, such as repairing blood vessel walls, regulation of immune status, and anti-oxidant activities. ${ }^{28}$ The increase in serum levels of Apo-E in this study may have been in response to the increase in cholesterol levels. It may also have been increased in response to other factors, such as oxidative stress, mechanical stress on the blood vessel walls due to the type of exposure mode used (intravenous), and immune response. Apo-E levels in serum were also increased with the $10 \mathrm{mg} / \mathrm{kg}$ dose. However, in this dosage group, the cholesterol level was significantly decreased, while the triglyceride level was significantly increased. Increased triglyceride levels leads to increased risk of cardiovascular disease, even in cases where cholesterol levels are not raised. ${ }^{29}$ With $1 \mathrm{mg} / \mathrm{kg}$, the serum level of triglycerides was also significantly increased, with a significant decrease in LDL cholesterol.

There were no apparent pathologies observed in the brain, heart, or testes of SDRs treated with Ni nanoparticles. The electrolyte profile showed a dose dependent decrease in potassium levels in serum. A decrease in serum potassium levels has been linked to increased risk of cardiac events, such as arrhythmia, ${ }^{30}$ and hypokalemia has also been associated with small cell lung cancers. ${ }^{31}$ Magnesium levels were also decreased with the $10 \mathrm{mg} / \mathrm{kg}$ and $20 \mathrm{mg} / \mathrm{kg}$ doses of Ni nanoparticles. Low levels of magnesium exacerbate potassium wasting and aggravate the adverse effects of hypokalemia on target tissues, such as the heart. ${ }^{32}$ It is estimated that more than $50 \%$ of clinically significant hypokalemia is concomitant with magnesium deficiency; however, hypomagnesemia does not necessarily indicate a magnesium deficiency. ${ }^{33}$ The hypokalemia and hypomagnesemia may also indicate changes in the glomerular filtration rate, but the histological sections of the kidney and biochemical analysis showed no evidence of acute renal toxicity. Further examinations using histochemical and molecular methods may help in elaborating on these findings.

Even though there was a significant decrease in CK levels, no significant changes in CK-MB levels were observed, suggesting that this decrease may have been due to other factors, such as liver injury. This is also supported by the normal histology of the heart in each of the dose groups. 


\section{Conclusion}

In this study, Ni nanoparticles induced acute inflammation in the lung, evidenced by foci of lymphocytic infiltrates in all dose groups and foamy macrophages in the high dose group. This was also supported by a high percentage of monocytes in the blood. Ni nanoparticles were seen to cause acute liver injury in the high dose group, as shown by the presence of inflammatory infiltrates in the liver and congestion leading to distortion of the normal liver morphology. This was supported by significant changes in the serum levels of total bilirubin and ALP. Ni nanoparticles also caused spleen injury leading to increased RBC production in the high dose group. The splenic injury may be a product of hypoxia or inflammatory mediators. Hypokalemia and hypomagnesemia leading to acute cardiac toxicity in the form of arrhythmias may also be implied. Therefore, intravenous injection of Ni nanoparticles may impact the liver, lung, spleen, and heart.

\section{Acknowledgments}

This work was partly supported by the National Nature Science Foundation of China (Grant No 81273111), the Foundations of Innovative Research Team of Educational Commission of Zhejiang Province (T200907), the Nature Science Foundation of Ningbo city (Grant No 2012A610185), the Ningbo Scientific Project (Grant No 2012C5019 and SZX11073), the Scientific Innovation Team Project of Ningbo (No 2011B82014), Innovative Research Team of Ningbo (2009B21002), and KC Wong Magna Fund in Ningbo University.

\section{Disclosure}

The authors report no conflicts of interest in this work.

\section{References}

1. Zhang D, Shen J, Wang C, Zhang X, Chen J. GSH-dependent iNOS and HO-1 mediated apoptosis of human Jurkat cells induced by nickel(II). Environ Toxicol. 2009;24(4):404-414.

2. Freitas M, Fernandes E. Zinc, cadmium and nickel increase the activation of NF- $\mathrm{KB}$ and the release of cytokines from THP-1 monocytic cells. Metallomics. 2011;3(11):1238-1243.

3. Pujalté I, Passagne I, Brouillaud B, et al. Cytotoxicity and oxidative stress induced by different metallic nanoparticles on human kidney cells. Part Fibre Toxicol. 2011;8:10.

4. Yang G, Xiao X, Rosen DG, et al. The biphasic role of NF-kappaB in progression and chemoresistance of ovarian cancer. Clin Cancer Res. 2011;17(8):2181-2194.

5. Peng XH, Qian X, Mao H, et al. Targeted magnetic iron oxide nanoparticles for tumor imaging and therapy. Int J Nanomedicine. 2008;3(3):311-321.

6. Delgado MD, Albajar M, Gomez-Casares MT, Batlle A, León J. MYC oncogene in myeloid neoplasias. Clin Transl Oncol. 2013;15(2):87-94.

7. Li Q, Kluz T, Sun H, Costa M. Mechanisms of c-myc degradation by nickel compounds and hypoxia. PLoS One. 2009;4(12):e8531.

8. Kaur R, Badea I. Nanodiamonds as novel nanomaterials for biomedical applications: drug delivery and imaging systems. Int J Nanomedicine. 2013;8:203-220.
9. Young MR, Yang HS, Colburn NH. Promising molecular targets for cancer prevention: AP-1, NF-kappa B and Pdcd4. Trends Mol Med. 2003;9(1):36-41.

10. Magaye R, Zhao J, Bowman L, Ding M. Genotoxicity and carcinogenicity of cobalt-, nickel- and copper-based nanoparticles. Exp Ther Med. 2012;4(4):551-561.

11. Prijic S, Sersa G. Magnetic nanoparticles as targeted delivery systems in oncology. Radiol Oncol. 2011;45(1):1-16.

12. Guo D, Wu C, Li J, et al. Synergistic Effect of Functionalized Nickel Nanoparticles and Quercetin on Inhibition of the SMMC-7721 Cells Proliferation. Nanoscale Res Lett. 2009;4(12):1395-1402.

13. Zhang R, Wang X, Wu C, et al. Synergistic enhancement effect of magnetic nanoparticles on anticancer drug accumulation in cancer cells. Nanotechnology. 2006;17(14):3622-3626.

14. Guo D, Wu C, Hu H, Wang X, Li X, Chen B. Study on the enhanced cellular uptake effect of daunorubicin on leukemia cells mediated via functionalized nickel nanoparticles. Biomed Mater. 2009;4(2):025013.

15. Aggarwal P, Hall JB, McLeland CB, Dobrovolskaia MA, McNeil SE. Nanoparticle interaction with plasma proteins as it relates to particle biodistribution, biocompatibility and therapeutic efficacy. Adv Drug Deliv Rev. 2009;61(6):428-437.

16. Hardie DG, Salt IP, Davies SP. Analysis of the role of the AMPactivated protein kinase in the response to cellular stress. Methods $\mathrm{Mol}$ Biol. 2000;99:63-74.

17. Zhao J, Shi X, Castranova V, Ding M. Occupational toxicology of nickel and nickel compounds. J Environ Pathol Toxicol Oncol. 2009;28(3): 177-208.

18. Zhao J, Castranova V. Toxicology of nanomaterials used in nanomedicine. J Toxicol Environ Health B Crit Rev. 2011;14(8):593-632.

19. Zhang XD, Wu HY, Wu D, et al. Toxicologic effects of gold nanoparticles in vivo by different administration routes. Int $J$ Nanomedicine. 2010;5:771-781.

20. Luzina IG, Todd NW, Iacono AT, Atamas SP. Roles of T lymphocytes in pulmonary fibrosis. J Leukoc Biol. 2008;83(2):237-244.

21. Gillespie PA, Kang GS, Elder A, et al. Pulmonary response after exposure to inhaled nickel hydroxide nanoparticles: short and long-term studies in mice. Nanotoxicology. 2010;4(1):106-119.

22. Yuasa K, Kanazawa T. [Foamy alveolar macrophages in various lung diseases, and their origin in rabbit lungs]. Nihon Kyobu Shikkan Gakkai Zasshi. 1995;33(7):715-722. Japanese.

23. MedlinePlus [homepage on the Internet]. Blood Differentials. Bethesda: US National Library of Medicine; 2013. Available from: http://www. nlm.nih.gov/medlineplus/ency/article/003657.htm. Accessed April 27, 2013.

24. Köhler D, Dellweg D. [Polycythemia]. Dtsch Med Wochenschr. 2010;135(46):2300-2303. German.

25. Kim $\mathrm{CH}$. Homeostatic and pathogenic extramedullary hematopoiesis. J Blood Med. 2010;1:13-19.

26. Abboud G, Kaplowitz N. Drug-induced liver injury. Drug Saf. 2007;30(4):277-294.

27. Giannini EG, Testa R, Savarino V. Liver enzyme alteration: a guide for clinicians. CMAJ. 2005;172(3):367-379.

28. Kozlov AI, Vershubskaia GG, Sanina ED, et al. [Blood serum concentration of lipids and lipoproteins and body composition]. Fiziol Cheloveka 2012;38(3):116-123. Russian.

29. Wierzbicki AS, Clarke RE, Viljoen A, Mikhailidis DP. Triglycerides: a case for treatment? Curr Opin Cardiol. 2012;27(4):398-404.

30. Macdonald JE, Struthers AD. What is the optimal serum potassium level in cardiovascular patients? J Am Coll Cardiol. 2004;43(2):155-161.

31. Martínez-Valles MA, Palafox-Cazarez A, Paredes-Avina JA. Severe hypokalemia, metabolic alkalosis and hypertension in a 54 year old male with ectopic ACTH syndrome: a case report. Cases J. 2009;2:6174.

32. Chakraborti S, Chakraborti T, Mandal M, Mandal A, Das S, Ghosh S. Protective role of magnesium in cardiovascular diseases: a review. $\mathrm{Mol}$ Cell Biochem. 2002;238(1-2):163-179.

33. Huang CL, Kuo E. Mechanism of hypokalemia in magnesium deficiency. J Am Soc Nephrol. 2007;18(10):2649-2652. 


\section{Publish your work in this journal}

The International Journal of Nanomedicine is an international, peerreviewed journal focusing on the application of nanotechnology in diagnostics, therapeutics, and drug delivery systems throughout the biomedical field. This journal is indexed on PubMed Central, MedLine, CAS, SciSearch $\AA$, Current Contents ${ }^{\circledR} /$ Clinical Medicine,

Journal Citation Reports/Science Edition, EMBase, Scopus and the Elsevier Bibliographic databases. The manuscript management system is completely online and includes a very quick and fair peer-review system, which is all easy to use. Visit http://www.dovepress.com/ testimonials.php to read real quotes from published authors.

Submit your manuscript here: http://www.dovepress.com/international-journal-of-nanomedicine-journal 